\title{
Apparent and quantitative loss of fatty acids and triacylglycerols at frying temperatures
}

\author{
By O. Berdeaux ${ }^{1}$, S. Marmesat ${ }^{2}$, J. Velasco ${ }^{2}$ and M.C. Dobarganes ${ }^{2, *}$ \\ 1 Plate-forme ChemoSens, Centre des Sciences du Goût et de l'Alimentation, UMR6265 CNRS, \\ UMR1324 INRA, Université de Bourgogne, Agrosup Dijon, 21000 Dijon, France \\ ${ }^{2}$ Instituto de la Grasa (CSIC). Avda. Padre García Tejero, 4. 41012- Sevilla-Spain \\ *Corresponding author: cdobar@cica.es
}

\section{RESUMEN}

Pérdida aparente y cuantitativa de ácidos grasos y especies de triglicéridos a temperatura de fritura.

Aceites de oliva y girasol se calentaron a $180^{\circ} \mathrm{C}$ durante 5,10 y 15 horas con el objetivo de definir los cambios en la concentración de ácidos grasos y especies de triglicéridos en condiciones de fritura. Se definen las diferencias entre la pérdida aparente y cuantitativa de ácidos grasos y triglicéridos que dependen de la forma de expresión de los resultados dando lugar en muchas ocasiones a interpretaciones erróneas. Así, a partir de la composición normalizada, podría deducirse que sólo el ácido graso más insaturado en los aceites (C18:2) se altera. Sin embargo, los datos cuantitativos muestran claramente que en muestras con niveles de compuestos polares entre 14.6 y $35.4 \%$, todos los ácidos grasos insaturados sufren degradación significativa en ambos aceites. Con respecto a los cambios en los distintos triglicéridos, su pérdida cuantitativa dependió no sólo de su número de dobles enlaces sino también del contenido del ácido más insaturado en ambos aceites.

PALABRAS CLAVE: Ácidos grasos - Compuestos polares - Ésteres metílicos de ácidos grasos polares - Fritura Triglicéridos.

\section{SUMMARY}

Apparent and quantitative loss of fatty acids and triacylglycerols at frying temperatures.

Olive and sunflower oils were heated at $180^{\circ} \mathrm{C}$ for 5,10 and 15 hours with the aim of defining the changes in the contents of fatty acid methyl esters (FAME) and triacylglycerols (TAG) under frying conditions. Differences between apparent and real loss of FAME or TAG are defined for an adequate interpretation of the changes taking place at high temperature. Such differences depend on the expression of the results and frequently result in erroneous conclusions. Results showed that from the normalized composition it could be deduced that only the most unsaturated FAME (C18:2) or TAG containing it was significantly altered. However, quantitative data indicated that all the unsaturated FAME were degraded in samples of olive oil and sunflower oil whose levels of alteration ranged from 14.6 to $35.4 \%$ polar compounds. With regard to TAG, their loss depended on both the number of double bonds and the concentration of the linoleyl group, which is the most unsaturated fatty acyl group in both oils.

KEY-WORDS: Fatty acids - Frying - Polar compounds Polar FAME -Triacylglycerols.

\section{INTRODUCTION}

A large number of papers dealing with comparative performance of different oils and fats at frying temperatures are published every year. Changes in fatty acid or triacylglycerol composition are analytical data usually presented, although their discussion is sometimes inadequate and misleading. The deficient interpretation is due to the form of expression of results, being the normalized composition one of the most used. This gives information on the percentages of each FAME or TAG on the whole analyzed. In fresh refined fats and oils, the normalized composition for FAME and TAG coincides in practice with the quantitative composition, as their contents are close to the total oil sample. However, when oils and fats are heated at frying temperatures a significant percentage of the fatty acyl groups of the TAG may alter to form oxidized TAG, dimeric and oligomeric TAG. As a result, the relative FAME composition given is that of the non-altered FAME fraction, which is the only one eluted in the GC analysis (Dobarganes and Pérez Camino, 1988; Dobarganes and Márquez-Ruiz, 2007).

The objective of this paper was to evaluate the loss of fatty acids and TAG at frying temperatures as well as describe the differences between apparent and quantitative loss of FAME and TAG based on the amounts of polar fatty acids and polar compounds.

\section{EXPERIMENTAL PART}

\subsection{Samples}

Olive oil and conventional sunflower oil were purchased from local outlets and thermoxidized at $180^{\circ} \mathrm{C}$ as described below.

\subsection{Heating procedure}

Thermal oxidation was carried out under strictly controlled conditions using a Rancimat (Metrohm, 
Herisau, Switzerland) apparatus. Samples of olive and sunflower oils were treated under identical conditions. Samples of $8 \pm 0.01 \mathrm{~g}$ oil were weighed out in Rancimat reaction vessels and these were inserted into the heating block of the Rancimat heated at $180 \pm 1^{\circ} \mathrm{C}$. Samples were heated in triplicates for 5, 10 and $15 \mathrm{~h}$. Rancimat instructions were carefully observed for temperature correction. No bubbling of air was applied during heating and the tubes were left open. This procedure was described in detail, including reproducibility data, in a previous publication (Barrera Arellano et al., 1997).

\subsection{Analytical determinations}

\subsubsection{Quantitation of polar compounds}

The content of total polar compounds was determined gravimetrically following the method proposed by the IUPAC (IUPAC, 1992c) with slight modifications. Thus, the non-polar and polar fractions were separated from $1 \mathrm{~g}$ of oil by silica column chromatography. The non-polar fraction, which contains the nonpolar TAG, was eluted with $150 \mathrm{~mL}$ of $\mathrm{n}$-hexane/diethyl ether $(90: 10, \mathrm{v} / \mathrm{v})$. A second fraction, which comprises the total polar compounds, was eluted with $150 \mathrm{~mL}$ of diethyl ether. After evaporation of solvents, the contents of the nonpolar and polar fractions were determined gravimetrically. Efficiency of the separation was checked out by thin layer chromatography using hexane/diethyl ether/acetic acid (80:20:1, v/v/v) for development of plates and exposure to iodine vapor to reveal the spots.

\subsubsection{Quantitation of nonpolar and polar fatty acid methyl esters (FAME)}

FAME were prepared from $300 \mathrm{mg}$ of oil by basecatalyzed transmethylation with sodium methoxide in TBME (Cecchi et al., 1985). After evaporation of TBME under nitrogen, FAME were dissolved in $2 \mathrm{~mL}$ of n-hexane-diethyl ether $(95: 5 \mathrm{v} / \mathrm{v})$ and then separated into two fractions of different polarity by silica column chromatography. A 40-cm length and 1 -cm i.d. glass column filled with $6 \mathrm{~g}$ of silica adjusted to a water content of $5 \%(\mathrm{~m} / \mathrm{m})$ was used. The nonpolar fraction was firstly eluted with $50 \mathrm{~mL}$ of n-hexane-diethyl ether $(95: 5 \mathrm{v} / \mathrm{v})$ and the polar fraction was obtained using $50 \mathrm{~mL}$ of diethyl ether. After evaporation of solvents, nonpolar and polar fatty acids were determined gravimetrically. The efficiency of the separation was checked out by TLC using hexane-diethyl ether-acetic acid (80:20:1 $\mathrm{v} / \mathrm{v} / \mathrm{v}$ ) for development of plates and exposure to iodine vapor to reveal the spots.

\subsubsection{Fatty acid composition}

Fatty acid composition was determined by GC after derivatization of the oils to FAME with $2 \mathrm{~N} \mathrm{KOH}$ in methanol, according to the IUPAC Standard Method (IUPAC, 1992a; 1992b). An Agilent 6890 gas chromatography system (Palo Alto, CA) equipped with a split/split-less injector, an Innowax capillary column (30 m length, $0.25 \mathrm{~mm}$ i.d., 0.20 $\mu \mathrm{m}$ film thickness) and a flame ionization detector (FID) was used. Hydrogen was used as carrier gas. The detector and injector temperatures were $250^{\circ} \mathrm{C}$. The initial oven temperature was $180^{\circ} \mathrm{C}$ and a temperature gradient from 180 to $220^{\circ} \mathrm{C}$ at $3^{\circ} \mathrm{C} \mathrm{min}^{-1}$ was applied. Injections were performed using a split ratio of 1:50.

\subsubsection{Triacylglycerol (TAG) composition}

TAG species were determined by GC using an Agilent 6890 chromatograph (Palo Alto, CA) equipped with a split/split-less injector, a Quadrex Aluminum-Clad 400-65HT capillary column (30 m length, $0.25 \mathrm{~mm}$ i.d., $0.1 \mu \mathrm{m}$ film thickness; Woodbridge, CT) and a FID. Hydrogen was used as carrier gas. The injector and detector temperatures were 360 and $370^{\circ} \mathrm{C}$, respectively, the oven temperature was maintained at $335^{\circ} \mathrm{C}$, and a head pressure gradient from 100 to $180 \mathrm{kPa}$ was applied. A linear gas rate of $50 \mathrm{~cm} \mathrm{~s}^{-1}$ and a split ratio of 1:80 were used (Fernández-Moya et al., 2000). The TAG species were identified and the data corrected for the relative response of the FID (Carelli and Cert, 1993).

\section{RESULTS AND DISCUSSION}

Table 1 shows results for polar compounds and polar fatty acids. The olive oil had a higher thermostability although no great differences were found between the two oils in spite of their differences in composition. Under the conditions applied, the polar compounds were between 14.6 and $35.4 \%$, which are normal contents in used frying fats and oils (Dobarganes and MárquezRuíz, 1998). After 10-hour heating, both oils showed around $25 \%$ polar compounds, limit established in most of the present regulations to discard frying oils and fats for human consumption. Polar FAME is a measure of the altered fatty acids and is considered a good measurement of thermoxidative degradation. Results showed values that ranged from 5.4 to $17.5 \%$. The ratio between total polar FAME and polar compounds provides a measurement of the average of polar fatty acids present in polar TAG. For instance, a ratio of 0.37 indicates that $37 \%$ of the fatty acids included in polar compounds are polar fatty acids, while $63 \%$ are consequently nonaltered fatty acids. The ratio increased with the level of degradation and it was similar for similar levels of polar compounds (Table 1).

Table 2 shows the changes in fatty acid composition for both oils after different periods of heating. As expected, the level of the most unsaturated fatty acid (C18:2) decreased with 
Table 1

Polar compounds and polar fatty acids (FAME) in olive and sunflower oils heated at $180^{\circ} \mathrm{C}$ for 5,10 and 15 hours

\begin{tabular}{lcccc}
\hline Oil & $\begin{array}{c}\text { Heating time } \\
\text { (h) }\end{array}$ & $\begin{array}{c}\text { Polar compounds } \\
\text { (wt\% on oil) }\end{array}$ & $\begin{array}{c}\text { Polar FAME } \\
\text { (wt\% on oil) }\end{array}$ & $\begin{array}{c}\text { Polar FAME/Polar } \\
\text { compounds }\end{array}$ \\
\hline Olive & 0 & $4.4 \pm 0.14^{*}$ & - & - \\
& 5 & $14.6 \pm 0.14$ & $5.4 \pm 0.21$ & 0.37 \\
& 10 & $22.8 \pm 0.02$ & $9.9 \pm 0.28$ & 0.43 \\
Sunflower & 15 & $30.8 \pm 0.07$ & $15.5 \pm 0.28$ & 0.50 \\
& 0 & $3.6 \pm 0.14$ & - & - \\
& 5 & $17.2 \pm 0.35$ & $6.5 \pm 0.42$ & 0.38 \\
& 10 & $26.6 \pm 0.07$ & $12.2 \pm 0.07$ & 0.46 \\
& 15 & $35.4 \pm 0.21$ & $17.5 \pm 0.28$ & 0.49 \\
\hline
\end{tabular}

* mean \pm standard deviation $(n=3)$.

Table 2

Fatty acid composition (\%) in olive and sunflower oils heated at $180^{\circ} \mathrm{C}$ for 5,10 and 15 hours

\begin{tabular}{lccccccc}
\hline \multicolumn{1}{c}{ Oil } & $\begin{array}{c}\text { Heating time } \\
(\mathbf{h})\end{array}$ & $\mathbf{C 1 6 : 0}$ & $\mathbf{C 1 6 : 1}$ & $\mathbf{C 1 8 : 0}$ & $\mathbf{C 1 8 : 1}$ & $\mathbf{C 1 8 : 2}$ & Others \\
\hline Olive & 0 & 11.1 & 0.9 & 2.6 & 76.2 & 7.7 & 1.5 \\
& 5 & 11.6 & 0.9 & 2.8 & 76.5 & 6.7 & 1.5 \\
& 10 & 12.0 & 0.9 & 3.0 & 76.4 & 5.8 & 2.0 \\
\multirow{3}{*}{ Sunflower } & 15 & 12.8 & 0.9 & 3.0 & 76.3 & 5.1 & 1.9 \\
& 0 & 6.2 & $\operatorname{tr}$ & 4.6 & 27.7 & 59.8 & 1.7 \\
& 5 & 6.8 & $\operatorname{tr}$ & 4.9 & 27.7 & 58.2 & 2.5 \\
& 10 & 6.8 & $\operatorname{tr}$ & 5.1 & 28.3 & 58.0 & 1.8 \\
& 15 & 7.4 & $\operatorname{tr}$ & 5.4 & 29.4 & 56.5 & 1.3 \\
\hline
\end{tabular}

tr, traces.

heating time and, apparently, C18:2 was the only fatty acid that was degraded. This fact is remarked in a significant number of papers suggesting that oleic acid does not change during heating and frying. Moreover, as it could be apparently deduced from data in Table 2, it has been often concluded that $\mathrm{C} 18: 1$ and saturated fatty acids even increase after heating. However, these changes are misleading because of the way of expression of FAME data as the percentage of each fatty acid on the total content of those analyzed or normalized composition, i.e. all the rows add up to 100. In fact this is the relative FAME composition of the nonaltered FAME fraction, which is the only fraction eluted in the GC analysis. Due to their high polarity the altered fatty acids are normally adsorbed in the GC column and do not elute under the analytical conditions applied.

Table 3 lists data which have been modified considering the content of nonpolar FAME in the samples to show quantitative changes in FAME expressed on the oil weight. In the first column of
Table 3 the real content of FAME (100 - \% polar FAME) has been included and the new data have been calculated to add up to the nonpolar FAME in each row. Assuming that initially the content of FAME is close to the sample weight $(100 \%)$, it can be observed that all the unsaturated fatty acids decreased meanwhile the saturated fatty acids remained at their initial levels due to their high stability. In Table 4 apparent and real losses of the different fatty acids have been calculated for 10-hour heating, when the percentages of polar compounds were around the limit for frying oil rejection ( $25 \%$ polar compounds) in both oils. The results indicate that, as expected, the loss of each unsaturated fatty acid was higher as its degree of unsaturation increases.

Based on the absence of changes in saturated fatty acids, we proposed an indirect measurement of the thermoxidative alteration through polar FAME by considering the major saturated fatty acid unchanged (Dobarganes and Pérez-Camino, 1988). Table 5 shows the FAME composition 
Table 3

Quantitation of fatty acids (wt\% on oil) in olive and sunflower oils heated at $180^{\circ} \mathrm{C}$ for 5,10 and 15 hours

\begin{tabular}{lcccccccc}
\hline Oil & $\begin{array}{c}\text { Heating time } \\
(\mathbf{h})\end{array}$ & $\begin{array}{c}\text { Nonpolar } \\
\text { FAME }\end{array}$ & $\mathbf{C 1 6 : 0}$ & $\mathbf{C 1 6 : 1}$ & $\mathbf{C 1 8 : 0}$ & $\mathbf{C 1 8 : 1}$ & $\mathbf{C 1 8 : 2}$ & Others \\
\hline Olive & 0 & 100 & 11.1 & 0.9 & 2.6 & 76.2 & 7.7 & 1.5 \\
& 5 & 94.7 & 11.0 & 0.9 & 2.7 & 72.4 & 6.3 & 1.4 \\
& 10 & 90.1 & 10.8 & 0.8 & 2.7 & 68.8 & 5.2 & 1.8 \\
& 15 & 84.5 & 10.8 & 0.8 & 2.6 & 64.5 & 4.3 & 1.6 \\
Sunflower & 0 & 100 & 6.2 & $\operatorname{tr}$ & 4.6 & 27.7 & 59.8 & 1.7 \\
& 5 & 93.3 & 6.3 & $\operatorname{tr}$ & 4.6 & 25.8 & 54.3 & 2.3 \\
& 10 & 87.9 & 6.0 & $\operatorname{tr}$ & 4.5 & 24.8 & 51.0 & 1.6 \\
& 15 & 82.2 & 6.1 & $\operatorname{tr}$ & 4.4 & 24.1 & 46.4 & 1.1 \\
\hline
\end{tabular}

tr, traces.

Tabla 4

Apparent and quantitative loss of unsaturated fatty acids (\%) in olive and sunflower oils heated at $180^{\circ} \mathrm{C}$ for 10 hours

\begin{tabular}{clccc}
\hline \multicolumn{1}{c}{ Oil } & Loss & C 16:1 & C18:1 & C18:2 \\
\hline Olive & Apparent & 0 & 0 & 25.7 \\
& Quantitative & 11.1 & 9.7 & 32.5 \\
\multirow{4}{*}{ Sunflower } & Apparent & - & 0 & 3.0 \\
& Quantitative & - & 10.5 & 14.7 \\
\hline
\end{tabular}

considering constant the percentage of C16:0. The estimated content of nonpolar FAME included in the last column was close to that obtained by adsorption chromatography (Table 3). The conclusions drawn from the FAME composition in Table 5 are the same as those obtained from quantitative data in Table 3.

Tables 6 and 7 show normalized composition of TAG for the samples of olive and sunflower oil, respectively. The nonaltered TAG fraction obtained in the determination of polar compounds was used

Table 5

Estimated quantitation of FAME (wt\% on oil) by maintaining constant the initial content of the major saturated fatty acid

\begin{tabular}{lcccccccc}
\hline Oil & $\begin{array}{c}\text { Heating time } \\
(\mathbf{h})\end{array}$ & $\mathbf{C 1 6 : 0}$ & $\mathbf{C 1 6 : 1}$ & $\mathbf{C 1 8 : 0}$ & $\mathbf{C 1 8 : 1}$ & $\mathbf{C 1 8 : 2}$ & Others & $\begin{array}{c}\text { Estimated } \\
\text { nonpolar FAME }\end{array}$ \\
\hline Olive & 0 & 11.1 & 0.9 & 2.6 & 76.2 & 7.7 & 1.5 & 100.0 \\
& 5 & 11.1 & 0.9 & 2.7 & 73.2 & 6.4 & 1.4 & 95.7 \\
& 10 & 11.1 & 0.8 & 2.8 & 70.7 & 5.4 & 1.9 & 92.6 \\
Sunflower & 15 & 11.1 & 0.8 & 2.6 & 66.2 & 4.4 & 1.6 & 86.7 \\
& 0 & 6.2 & $\operatorname{tr}$ & 4.6 & 27.7 & 59.8 & 1.7 & 100.0 \\
& 5 & 6.2 & $\operatorname{tr}$ & 4.5 & 25.3 & 53.1 & 2.3 & 91.3 \\
& 10 & 6.2 & $\operatorname{tr}$ & 4.7 & 25.8 & 52.9 & 1.6 & 91.2 \\
\hline
\end{tabular}

tr, traces.

Table 6

Triacylglycerol composition (\%) in olive oil heated at $180^{\circ} \mathrm{C}$ for 5,10 and 15 hours

\begin{tabular}{rrrrrrrrrr}
\hline $\begin{array}{c}\text { Heating time } \\
\text { (h) }\end{array}$ & POP & PLP & POS & POO & POL & SOO & OOO & SOL & OOL \\
\hline $\mathbf{0}$ & 3.5 & 1.2 & 1.3 & 24.3 & 6.2 & 5.2 & 43.4 & 4.2 & 9.5 \\
$\mathbf{5}$ & 3.9 & 1.1 & 1.4 & 25.1 & 5.8 & 5.3 & 43.4 & 3.9 & 8.4 \\
$\mathbf{1 0}$ & 4.1 & 1.2 & 1.4 & 26.2 & 5.5 & 5.6 & 43.6 & 3.8 & 7.2 \\
$\mathbf{1 5}$ & 4.3 & 1.2 & 1.6 & 26.7 & 5.0 & 5.7 & 43.5 & 3.8 & 6.4 \\
\hline
\end{tabular}


Table 7

Triacylglycerol composition (\%) in sunflower oil heated at $180^{\circ} \mathrm{C}$ for 5,10 and 15 hours

\begin{tabular}{|c|c|c|c|c|c|c|c|c|c|c|c|c|c|c|}
\hline $\begin{array}{l}\text { Heating } \\
\text { time (h) }\end{array}$ & POP & PLP & POS & POO & PLS & POL & PLL & soo & 000 & SOL & OOL & SLL & OLL & LLL \\
\hline 0 & 0.3 & 1.1 & 0.3 & 2.1 & 1.4 & 6.7 & 10.1 & 1.3 & 5.6 & 3.7 & 11.3 & 7.3 & 26.5 & 22.3 \\
\hline 5 & 0.3 & 1.0 & 0.4 & 2.4 & 1.4 & 7.0 & 10.0 & 1.5 & 6.5 & 3.9 & 12.1 & 6.9 & 26.0 & 20.6 \\
\hline 10 & 0.4 & 1.2 & 0.5 & 2.6 & 1.5 & 7.3 & 9.8 & 1.7 & 6.8 & 4.2 & 12.3 & 7.1 & 25.1 & 19.0 \\
\hline 15 & 0.4 & 1.2 & 0.5 & 2.8 & 1.7 & 7.4 & 9.5 & 2.0 & 8.0 & 4.7 & 12.7 & 7.1 & 24.3 & 17.6 \\
\hline
\end{tabular}

for the analysis of TAG composition to avoid impurification of the chromatographic column by the altered compounds which do not elute under the analytical conditions applied. Only TAG containing C18:2 decreased in both oils giving again the apparent impression that $\mathrm{C} 18: 1$ remained unaltered. Similarly to that commented for FAME, the normalized composition can be transformed into quantitative data by considering that, after heating, the nonpolar TAG are only a part of the sample. In Tables 8 and 9 the percentages of nonpolar TAG deduced from polar compounds (100-\% polar compounds) have been included in the first column to calculate the real contents of TAG expressed on weight sample. Great differences were observed between apparent and real losses of TAG species (Table 10). From quantitative data, it was observed that, for example, around $25 \%$ polar compounds, all the TAG underwent degradation because all contained unsaturated fatty acids. The only exceptions were those TAG containing one oleyl group as the only unsaturated fatty acyl in sunflower oil, probably due to the high concentration of TAG containing the linoleyl group, which is more susceptible to degradation. As expected, the higher the degree of unsaturation, the higher the loss of TAG. However, it is also interesting to observe that for TAG species with the same number of double bonds, the degradation was more rapid as the content of linoleyl groups increased. This is the case

Table 8

Quantitation of triacylglycerols (wt $\%$ on oil) in olive oil heated at $180^{\circ} \mathrm{C}$ for 5,10 and 15 hours

\begin{tabular}{rcccccccccc}
\hline $\begin{array}{c}\text { Heating time } \\
\text { (h) }\end{array}$ & $\begin{array}{c}\text { Non polar } \\
\text { TAG }\end{array}$ & POP & PLP & POS & POO & POL & SOO & OOO & SOL & OOL \\
\hline $\mathbf{0}$ & 95.6 & 3.3 & 1.1 & 1.2 & 23.2 & 5.9 & 5.0 & 41.5 & 4.0 & 9.1 \\
$\mathbf{5}$ & 85.4 & 3.3 & 0.9 & 1.2 & 21.4 & 5.0 & 4.5 & 37.1 & 3.3 & 7.2 \\
$\mathbf{1 0}$ & 77.2 & 3.2 & 0.9 & 1.1 & 20.2 & 4.2 & 4.3 & 33.7 & 2.9 & 5.6 \\
$\mathbf{1 5}$ & 69.2 & 3.0 & 0.8 & 1.1 & 18.5 & 3.5 & 3.9 & 30.1 & 2.6 & 4.4 \\
\hline
\end{tabular}

Table 9

Quantitation of triacylglycerols (wt\% on oil) in sunflower oil heated at $180^{\circ} \mathrm{C}$ for 5,10 and 15 hours

\begin{tabular}{cccccccccccccccc}
\hline $\begin{array}{c}\text { Heating } \\
\text { time (h) }\end{array}$ & $\begin{array}{c}\text { Non polar } \\
\text { TAG) }\end{array}$ & POP & PLP & POS & POO & PLS & POL & PLL & SOO & OOO & SOL & OOL & SLL & OLL & LLL \\
\hline $\mathbf{0}$ & 96.4 & 0.3 & 1.1 & 0.3 & 2.0 & 1.3 & 6.5 & 9.7 & 1.3 & 5.4 & 3.6 & 10.9 & 7.0 & 25.5 & 21.5 \\
$\mathbf{5}$ & 82.8 & 0.2 & 0.8 & 0.3 & 2.0 & 1.2 & 5.8 & 8.3 & 1.2 & 5.4 & 3.2 & 10.0 & 5.7 & 21.5 & 17.1 \\
$\mathbf{1 0}$ & 73.4 & 0.3 & 0.9 & 0.4 & 1.9 & 1.1 & 5.4 & 7.2 & 1.2 & 5.0 & 3.1 & 9.0 & 5.2 & 18.4 & 14.0 \\
$\mathbf{1 5}$ & 64.6 & 0.3 & 0.8 & 0.3 & 1.8 & 1.1 & 4.8 & 6.1 & 1.3 & 5.0 & 3.0 & 8.2 & 4.6 & 15.7 & 11.4 \\
\hline
\end{tabular}

Table 10

Apparent and quantitative loss of unsaturated triacylglycerols (\%) in olive and sunflower oils heated at $180^{\circ} \mathrm{C}$ for 10 hours

\begin{tabular}{|c|c|c|c|c|c|c|c|c|c|c|c|c|c|c|c|}
\hline Oil & Loss & POP & PLP & POS & POO & PLS & POL & PLL & soo & 000 & SOL & OOL & SLL & OLL & LLL \\
\hline \multirow[t]{2}{*}{ Olive } & Apparent & 0 & 0 & 0 & 0 & - & 11.3 & - & 0 & 0 & 9.5 & 24.2 & - & - & - \\
\hline & Quantitative & 3.0 & 18.2 & 8.3 & 12.9 & - & 28.8 & - & 14.0 & 18.8 & 27.5 & 38.5 & - & - & - \\
\hline \multirow[t]{2}{*}{ Sunflower } & Apparent & 0 & 0 & 0 & 0 & 0 & 0 & 3.0 & 0 & 0 & 0 & 0 & 2.7 & 5.3 & 14.8 \\
\hline & Quantitative & 0 & 18.2 & 0 & 5.0 & 15.4 & 16.9 & 25.8 & 7.7 & 7.4 & 13.9 & 17.4 & 25.7 & 27.8 & 34.9 \\
\hline
\end{tabular}


of the pairs PLP/POO, POL/OOO or SOL/OOO in olive oil and of PLP/POO, PLS/POO, POL/OOO, SOL/OOO, PLL/OOL or SLL/OOL in sunflower oil.

To sum up, the following conclusions can be made from this study:

1. From the normalized composition, losses of fatty acids or TAG during heating of oils cannot be deduced because a significant part of the sample does not elute in the GC analysis.

2. Quantitative changes in FAME clearly demonstrated that at the levels of polar compounds close to $25 \%$ in oils heated at frying temperature, all the unsaturated fatty acids had undergone significant degradation. Their relative loss depended on both their concentration in the oil and their degree of unsaturation. However, saturated fatty acids remained at their initial levels.

3. By maintaining constant the level of the major saturated FAME, a measurement of the thermoxidative degradation can be easily obtained in dependent samples.

4. The loss of TAG was higher as their number of double bonds increases and particularly when the most unsaturated acyl group is present

\section{REFERENCES}

Barrera-Arellano D, Márquez-Ruiz G, Dobarganes MC. 1997. A simple procedure to evaluate the performance of fats and oils at frying temperatures. Grasas Aceites 48, 231-235.

Carelli AA, Cert A. 1993. Comparative study of the determination of triacylglycerol in vegetable oils using chromatographic techniques. J. Chromatogr. A 630, 213-222.
Cecchi G, S Biasini, Castano J. 1985. Méthanolyse Rapide des Huiles en Solvant. Rev. Franc. Corps Gras 32, 163-164.

Dobarganes MC, Pérez-Camino MC. 1988. Fatty acid composition: a useful tool for the determination of alteration level in heated fats. Rev. Franç. Corps Gras 35, 67-70.

Dobarganes MC, Márquez-Ruíz G. 1998. Regulation of used frying fats and validity of quick tests for discarding the fats. Grasas Aceites 49, 331-335.

Dobarganes MC, Márquez-Ruíz G. 2007. Formation and analysis of oxidized monomeric, dimeric and higher oligomeric triglycerides. In Deep Frying: Chemistry Nutrition and Practical Applications. 2nd edition. Ed. by M.D. Erickson. American Oil Chemists' Society, (Champaign, Illinois), pp 87-110.

Fernández-Moya V, Martínez-Force E; Garcés R. 2000. Identification of triacylglycerol species from highsaturated sunflower (Helianthus annuus) mutants. J. Agric. Food Chem. 48, 764-769.

IUPAC (1992a). Preparation of the fatty acid methyl esters 2.301. In Standard Methods for the Analysis of Oils, Fats and Derivatives, $7^{\text {th }}$ ed.; International Union of Pure and Applied Chemistry, Blackwell Scientific: Oxford, UK, 1992.

IUPAC (1992b). Gas-liquid chromatography of fatty acid methyl esters 2.302. In Standard Methods for the Analysis of Oils, Fats and Derivatives, $7^{\text {th }}$ ed.; International Union of Pure and Applied Chemistry, Blackwell Scientific: Oxford, UK, 1992.

IUPAC (1992c). Determination of polar compounds in frying fats 2.507. In Standard Methods for the Analysis of Oils, Fats and Derivatives, 7th ed.; International Union of Pure and Applied Chemistry, Blackwell Scientific: Oxford, UK, 1992.

Recibido: 5/3/12 Aceptado: $27 / 3 / 12$ 